\title{
LUÍS VIE SUGER As relações de poder entre a Igreja e o Estado francês no séc. XII
}

\author{
Maria do Carmo Parente Santos*
}

SINTESE - $O$ tema do nosso trabalho é a análise da obra Vie de Louis VI Le Gros, escrita pelo abade Suger. Esta crônica é a narrativa do reinado do monarca francês, Luís VI (1108-1137), feita pelo abade Suger, testemunha ocular dos acontecimentos nela narrados. No nosso entender a obra reveste-se de bastante interesse para o historiador, visto que através dela podemos tentar compreender como os intelectuais da Igreja relacionavam-se com o poder secular e os motivos que os levaram a apoiar ou condenar as determinaçōes reais.
ABSTRACT - Our theme is the analysis about Suger Abbot's work, named Vie de Louis VI Le Gros, written in twelfth century. This essay is the narrative of the reign of the french monarch, Luis VI (1108-1137) made by Suger Abbot's a live witness of the ocurences, which took place in that period. The understanding about the essay leds the historians to a way of great interest because they can visualize through history how the intellectuals of church coped with the centurial power hence the reasons that got them to support or to condemn the real determinations.

Em 1108, Luís, filho de Felipe I, é sagrado rei da França. É o quinto rei da dinastia capetíngia, a terceira familia a governar os destinos do reino franco.

Ele governará durante quase 30 anos e será pai de Luís VII, que a Igreja canonizou como S. Luís.

A personalidade de Luís VI é marcada por seus traços de coragem, determinação e audácia, sendo ele apresentado pelos historiadores como o protótipo do guerreiro medieval.

É justamente este fato, isto é, a acentuada tônica sobre a constante atuação guerreira deste rei que nos impõe uma reflexão - qual o motivo dela, ou melhor, o que significavam e o que expressavam as lutas intermitentes que pontificaram 0 reinado de Luís VI?

O ponto de partida para a resposta a essa indagação necessariamente deve ser a análise da própria questão do poder real na Idade Média, como ele era exercido, quais as bases que o legitimavam, que fatores o limitavam, como era percebido pelos diversos estamentos sociais que compunham a sociedade feudal.

Os trinta anos do reinado deste soberano estão inseridos numa época marcada por dramáticas transformações econômico-sociais que colocaram em xeque a própria estrutura feudal, caracterizada pela rígida hierarquia das ordens sociais e pelo imobilismo.

- Universidade do Estado do Rio de Janeiro - UERJ.

\begin{tabular}{|l|l|l|l|l|l|}
\hline VERTTAS & Porto Alegre & v. 40 & $n^{2} 159$ & Setembro 1995 & p. 391-403 \\
\hline
\end{tabular}


O crescimento demográfico, o renascimento comercial e urbano, o aparecimento de um novo grupo social - a burguesia - sacudiram as bases em que se legitimavam tanto o poder laico quanto o eclesiástico, gerando tensões que na maioria das vezes levavam a conflitos que se resolveram pelo uso da extrema violência, mas que ao longo do tempo apontaram para a necessidade da procura de um equilibrio entre as diversas instâncias de poder que coexistiam na sociedade.

A principal fonte para o conhecimento do reinado do pai de $S$. Luís é a obra escrita pelo Suger: Vie de Louis VI, Le Gros.

A leitura desta obra faz-nos entrar em contato com toda a turbulência política e social que abalava a França do século XII e que foi exposta pelo autor de forma minuciosa e muitas vezes dramática. Suger utiliza freqüentemente as palavras traição, vingança e crueldade para descrever os inúmeros episódios em que o poder real foi frontalmente contestado.

Amigo íntimo do soberano biografado, o autor condena veementemente a atitude dos insubmissos barões feudais, recriminando-os violentamente por sua insubordinação frente ao poder do monarca, a quem ele nos apresenta como um modelo de virtude e piedade.

Durante o seu reinado, Luis, o Gordo, sustentou uma contínua luta contra os barões salteadores estabelecidos em torreões fortificados na própria lle de France, contra a arrogância da feudalidade doméstica que, havendo monopolizado as mais altas dignidades palatinas, constituiam uma ameaça à própria sobrevivência da dinastia capentígia e, por fim, contra os grandes senhores que, detentores de vastíssimos feudos, governavam-nos de forma totalmente independente em relação ao monarca.

Suger, como já dissemos, usa as mais ásperas e duras palavras ao narrar os episódios em que a nobreza defende ferozmente seus privilégios, mas não devemos, contudo, perder de vista o fato de que a insubordinação ao rei não era uma atitude nova, pelo contrário, nova era a disposição do monarca em fazer sua autoridade reconhecida, respeitada pela feudalidade francesa, pois seus antecessores nunca haviam tentado empreender tal tarefa, isto porque o exercício do poder político na França do século XII encontrava-se pulverizado entre os diversos senhores que desfrutavam em suas terras das prerrogativas realengas e que tinham a sua autoridade reconhecida por todos os que nela habitavam. O rei, na realidade, era apenas um senhor feudal coroado. Tal situação está bem representada numa moeda cunhada durante o reinado de Hugo Capeto, o primeiro rei da dinastia. Nela está escrito: Hugo dusc gracia Dei rex (Hugo duque, rei pela graça de Deus).

A autoridade real era tênue, limitada e ineficiente, e a figura do rei legitimavase apenas pela sagração que lhe conferia a Igreja.

Para compreendermos melhor as dificuldades enfrentadas por Luis VI, bem como avaliarmos o alcance de suas vitórias, é necessário que tracemos algumas breves considerações sobre o processo que levara à debilidade do poder real e o conseqüente fortalecimento dos senhores feudais.

É também indispensável a compreensão do que significava a sagração do soberano pela Igreja e a importância deste ato a nível ideológico, como fator de legitimação do poder do monarca. 
A reflexão sobre esta delicada questão remete-nos à análise das relações entre a Igreja e o poder real.

O primeiro rei a ser sagrado pela Igreja foi Pepino que ascendeu ao trono após haver usurpado o poder que hereditariamente pertencia a uma outra linhagem, a dinastia merovingia.

Apresentava-se assim, ao primeiro rei da dinastia carolingia, a necessidade de buscar uma base que legitimasse seu poder, base esta que não podia ser conseguida recorrendo-se a tradição ou a argumentos baseados na raça e no sangue.

Pepino então ousou. Para ele tratava-se de legitimar sua autoridade ligando-a não à ordem humana - falha, sempre precária e por isso mesmo passível a todo momento de contestação - mas alicerçá-la através da ligação com a própria ordem sobrenatural e transcendente e, por conseguinte, incontestável.

Assim, apela para o papa no sentido que reconheça seu direito ao trono.

Zacarias ao atender ao apelo de Pepino e aprovar sua permanência como rei dos francos também o faz atendendo à diretriz de estabilidade do corpo social, viga mestra na construção a que persistentemente os ideólogos da Igreja vinham se dedicando, a idéia de ordem humana como reflexo da ordem divina, a sociedade humana como resultado da vontade de Deus. Nela, cada função teria um lugar e executaria suas obrigações. Se Pepino já exercia o poder real, ao papa cabia simplesmente legitimá-lo.

Essa legitimação era realizada através da cerimônia de sagração, ocasião na qual os bispos ao verter o santo óleo sobre o monarca "este impregnava o seu corpo, enchia-o da força do Senhor e de todos os poderes do Além". ${ }^{1}$

O temor e o respeito despertado nos súditos pelo poder real originaram-se, sem sombra de dúvida, nesta cerimônia que sobrenaturalizava a figura do rei.

Além disso, a função real reveste-se, através de sua ligação com a Igreja, de aspectos mais abrangentes do que simplesmente a de rei como condutor do povo à guerra, concepção originária dos povos germânicos. O monarca é agora, além de chefe militar, o mantenedor da paz e da justiça entre o seu povo, o que protege 0 fraco contra 0 abuso dos poderosos, o que defende a Igreja da pilhagem daqueles que cobiçam o ouro de seus altares, riquezas destinadas à exaltação do Altíssimo, mas que podem sempre tornar-se alvo da rapinagem dos que não temem a Deus.

Está assim investido de uma missão que o coloca no topo da hierarquia social e que o obriga a pesadas tarefas que podem ser avaliadas através da carta que $\mathrm{Al}-$ cuíno em 799 escreve para Carlos Magno:

"Que a Graça divina vos dê a liberdade de vos apoderar do Saxe e do seu povo infame para governar os reinos, fazer a justiça, restaurar as igrejas, corrigir o povo, honrar exatamente cada pessoa e cada dignidade, defender os oprimidos, fazer as leis, consolar os peregrinos e mostrar em toda a parte e para todos o caminho da vida celeste". ${ }^{2}$

Assim, podemos concluir que o governo do monarca não objetivava única e tão somente a direção dos negócios terrestres mas revestia-se de uma significação maior que era a de conduzir o povo em direção ao plano espiritual e eterno.

1 DUBY, Georges. O tempo das catedrais. Lisboa, Editorial Stampa. p. 22.

2 Citado por Jacques Paul, L'Église et la Culture en Occident IX - XIII siècles - Tomo I - La santification de l'orde temporel et spirituel - Paris, PUF, 1986. p. 60. 
Embora pelo que foi exposto possamos concluir que a figura real era legitimada por uma ideologia coerente e profundamente ajustada à mentalidade cristã da época, não podemos acreditar que só ela era responsável pela obediência ao poder real. Não, é impossível esquecermos que havia também uma base material que sustentava este poder. Era a posse da terra.

O monarca através das campanhas militares tornou-se possuidor de um enorme patrimônio fundiário que ele generosamente distribuia para aqueles que the eram fiéis e o serviam.

O butim obtido nas guerras também era objeto de distribuição entre os vassalos que encaravam o serviço ao monarca como um meio de obter riqueza, prestígio e poder.

A partir do séc. IX, a impotência do poder real é incontestável e a corte real deixa de ser o centro das atenções, para onde todos os grandes senhores do reino acorriam.

A explicação para isto está no término das guerras de conquista, que faz com que o rei já não tenha com o que pagar o serviço de seus guerreiros. Por isso, eles agora já se deixam ficar em seus próprios domínios, imensas propriedades onde vivem, eles próprios verdadeiros reis, subjugando um campesinato que neles reconhecia a autoridade e para quem o rei era uma entidade tão distante e inalcançável quanto o próprio Deus.

Somam-se a isto as turbulências políticas advindas da divisão do império franco pelo Tratado de Verdun e as invasões normandas, sarracenas e húngaras que aumentaram o poder dos nobres locais - únicos que podiam defender a população contra os ataques - e acelerar o processo de decadência do poder real.

Os nobres arrogam-se poderes que antes eram exclusivos do rei: o poder militar, o poder de julgar e punir.

Esta feudalidade arrogante e belicosa desafia o poder real e proclama bem alto sua independência frente a ele.

A leitura de um documento datado do séc. XII dá-nos uma idéia da situação de dispersão política e de anarquia militar em que o território francês encontravase mergulhado:

"Os homens de grande riqueza e de nobre nascimento passam a maior parte de seu tempo em hostilidades e batalhas - escreve um cronista do principio do séc. XII - a fim de se proteger dos inimigos, de vencer os iguais e de oprimir os fracos, têm por costume levantar uma massa de terra o mais alto possivel, de cavar em redor um fosso largo e fundo; no cimo uma muralha feita de troncos desbastados, solidamente unidos uns aos outros". ${ }^{3}$

A observação de uma tal situação provoca uma pergunta inevitável: por que o poder real não se extinguiu totalmente, quando cada chefe de fortaleza aparece como um pequeno soberano?

A resposta está justamente no aspecto quase divino de que o rei estava revestido, ou seja, ele era sagrado. A Igreja assim o fizera através da cerimônia de sagração quando o ungia com os santos óleos. A sacralidade era um atributo essencial de soberano, atributo que só poderia ser conseguido através da Igreja, que, contudo, se negava a dispensá-lo a qualquer um outro que não um carolíngio.

3 PERRY, Édouard. "A Idade Média". In: História Geral das Civilizaçöes. S. Paulo: Difel, 1974. p. 45. 
Percebemos, então, que havia como uma simbiose entre os dois poderes, o espiritual e o temporal.

A aliança entre o papado e os diversos monarcas será, contudo, origem de muitos problemas para a Igreja que no século XI encontra-se numa profunda decadência moral e com seu prestígio totalmente abalado.

Tal situação devia-se aos dois maiores males que grassavam em todo o continente europeu: o nicolaísmo e a simonia. Eles derivavam-se da excessiva influência laica nos assuntos eclesiásticos.

A crise se tornará mais aguda quando o papado se tornar um quase prisioneiro dos imperadores alemães que, se a princípio estenderam a sua proteção livrando-o do domínio da nobreza italiana, não tardaram em imiscuir-se, de maneira bastante severa, nos assuntos pertinentes à esfera da autoridade papal.

Se a princípio o papado dobrou-se ao poder do soberano alemão, esta situação não se perpetuará, pois ao ascender ao trono de Pedro, o enérgico Gregório VII empreenderá uma feroz oposição a Henrique IV, objetivando livrar a Igreja do poder imperial.

Este difícil empreendimento é realizado pela reforma gregoriana que, através do desenvolvimento do Direito Canônico sustentou a idéia da superioridade moral do papa frente a qualquer soberano. A supremacia do papado já fora formulada no tempo da decadência carolíngia nas coleções canônicas pseudo-isidorianas, mas ela é "retomada, enriquecida e proclamada num tom mais rigoroso na metade do séc. $\mathrm{XI}^{*}{ }^{4}$

A acirrada disputa que se estabelece entre o papa e o imperador explica a severidade do Dictatus Papae (1075) que atacava o poder dos reis num ponto vital; no seu último item afirma "que o pontífice pode liberar os súditos da fidelidade a um monarca iníquo". 5

A reforma gregoriana fez com que os papas passassem a intervir mais ativamente nas monarquias cristãs.

No caso da França, esta interferência é mais sentida devido à fraqueza da monarquia capetíngia que faz com que os papas sempre que incomodados por seus inimigos na península itálica, aportassem na França realizando aí grandes estadias e assenhoreando-se da direção dos grandes casos, como, por exemplo, a organização das Cruzadas e a aplicação da Trégua de Deus.

A conduta desregrada de Felipe I, pai de Luís VI, segundo muitos, preguiçoso, sensual, glutão, bígamo e até mesmo incestuoso e simoníaco, fez com que ele não contasse com qualquer apoio para opor-se aos papas Gregório VII e, posteriormente, Urbano II.

Todas estas acusações não eram levianas e a elas juntaram-se o fato de que o rei fora displicente na sua tarefa de proteger a Igreja galicana - como era sua obrigação - o que a havia levado a um estado de decadência moral e financeira, tendo as abadias e os bispados caido nas mãos de prelados que em nada se diferenciavam dos outros nobres.

4 DUBY, Georges. Obra citada p. 43.

5 GREGORIO VII, "Registrum" P. L. CXLVIII apud Jaime Pinsky. 
A energia de Gregório VII e Urbano II e seus legados assegura o triunfo de suas idéias na França, sendo que a autoridade dos bispos e arcebispos foi restabelecida e as liberdades galicanas foram cerceadas.

É essa a situação que, ao morrer, Felipe I lega a Luís, o gordo. Este, mesmo que quisesse, não poderia reagir às exigências do papado e, muito menos, pensar em restabelecer as práticas simoníacas correndo o risco de indispor-se com a Santa Sé, pois o jovem soberano encontrava-se ameaçado em seu píóprio domínio pela brigandage feudal, precisando, portanto, contar com o apoio de homens e dinheiro do seu clero, bem como com a benevolência do papado. Este, por sua vez, sente-se ainda ameaçado pelo imperador alemão, que não se conforma em perder a ascendência que tradicionalmente o império mantinha sobre a Igreja.

Deste modo, foi muito confortável para Luís VI colocar-se como o defensor das igrejas, dos pobres, das viúvas e dos órfãos, como nos apresenta Suger:

"en rapportant avec notre plume la respectueuse dévotion pour les églises de Dieu et l'admi-
rable activité politique de celui dont aucune vicissitude des temps ne saurait effacer le sou-
venir, s'arrêter les prières aidentes et secourables de l'Eglise consideration des bienfaits re-
çus de lui avec abondance. Ainsi grandissait le jeune et renommé Louis, agréable, aimable e
bienveillant au point que certaines gens le tenaient pour simple d'esprit, illustre et coura-
geux défenseur du royaume paterne, il pourvoyait aux intérêts des églises et, ce qui durant
longtemps n'avait pas été dans les habitudes, veillait au repos du clergé, des travailleurs et
des pauvres".

E por que tanto as igrejas quanto os pobres precisavam ser defendidos? Que ameaça pesava sobre eles?

Eles precisavam ser defendidos da cobiça dos grandes senhores que, com seus exércitos particulares, praticavam toda a sorte de abusos e pilhagens sem conhecer nenhum limite à sua ambição.

Luís atacou esses poderosos senhores não como vassalos, não como adversários, mas simplesmente como malfeitores que deveriam prestar contas à justiça.

É desta maneira que o cronista descreve a ação do rei Luís, quando luta contra Bouchard de Montmorency e seus cúmplices, nobres que espoliavam a abadia de Saint Denis:

"[...] il ravagea la terre de Bouchard et, bouleverant les lieux fortifiés et les basses-cours a l'exception du château, la mit dans le pire état, l'accablant sous le poids des incendies, de la faim, des coupes d'epée. Alors, avec les chevaliers français et les Flamands, ceux de son oncle Robert et les siens propres, il mit le siège autour. Par ces coups et d'autres semblabes, écrasants pour Bouchard, il humilia celui-ci, le courba sous sa volanté et son bon plaisir, et apaisa en obtenant satisfaction la querelle qui avait causé les troubles". 7

É oportuno ressaltarmos que os estabelecimentos eclesiásticos - abadias e mosteiros - eram alvo constante da rapacidade de alguns nobres devido à riqueza material que possuiam, principalmente objetos de ouro e prata. Tal acontecia devido à mentalidade medieval que acreditava que a prece dos religiosos podia aliviar a culpa dos pecadores. Assim, muitos nobres e reis ao morrerem doavam uma parte de sua herança para estas instituições religiosas, na esperança que suas preces

6 SUGER. Vie de Louis VI Le Gros. Paris : Libraire Ancienne Honoré Champion Écliteue, 1929. p. 3.

7 Id. ibid. p. 26. 
lhes abririam as portas do céu. Ao acumular através destas doações um enorme patrimônio, estes estabelecimentos tornaram-se alvo de cobiça de alguns homens que não pareciam preocupar-se com a salvação de suas próprias almas.

Estes nobres em determinadas ocasiões chegavam a estabelecer coligações, como no episódio em que o monarca luta contra Ebles de Roucy que conseguiu reunir outros barões insatisfeitos para lutar contra o jovem soberano. Isto tornava a ação real ainda mais perigosa e difícil e ela é descrita pelo cronista de uma forma em que o rei é apresentado como o implacável justiceiro que empunha a espada para proteger os fracos e ressarci-los dos prejuízos causados pela cobiça dos nobres.

\footnotetext{
"C'est bien fait: il fallait que les pilards fussent pillés à leur tour, que les bourreaux fussent soumis aux mêmes tortures, voire a de plus dures, que leurs victimes. Telle était l'ardeur du seigneur et de l'ost que, tant qu'ils furent en campagne, ils prirent à peine du repos, ou plutôt qu'à l'exception du samedi et du dimanche, ils n'en prirent jamais: ils ne cessaient, soit d'engager le combat la lance ou l'epée à la main, soit de venger par la ruine de ses terres les violences du comte".
}

Mas a autoridade real não era contestada somente pelo baronato - que estabelecido em seus feudos desafiava o jovem Luis.

$\mathrm{Na}$ própria corte, o perigo fazia-se presente na figura de uma ambiciosa e ameaçadora feudalidade doméstica que pretendia monopolizar as mais altas dignidades palatinas, convertendo-as em benefícios hereditários. Tal situação lembrava a atuação dos Pepínidas que haviam acabado por destronar os Merovingios. Tais pretensões eram acalentadas por Étienne Garlande, senescal e chanceler. Luís reagiu com severidade, não se deixando atemorizar pela importância social dos Garlande, retirou-lhe a dignidade de que estava investido. $O$ chanceler revoltou-se, pegando em armas contra o rei.

Luís após tê-lo obrigado a submeter-se a sua autoridade, perdoou-o e devolveu-lhe o senescalato.

Embora isto pareça uma fraqueza do rei, temos que considerar a reflexão de Calmette sobre o caso:

"Louis VI engage la lutte, enlève leurs dignités aux Garlande. Étienne résiste armes en mains. L'alerte a été chaude, mais le tournant est franchi: désormais, l'eprit féodal est en recul. Le pardon obtenu par Étienne de Garlande et son retour à la chancellerie n'infirment en vieu la victorie remportée par la royauté". ${ }^{9}$

No caso em questão há um aspecto significativo a ser considerado, o fato de que Étienne Garlande era bispo. Embora a própria Igreja afirmasse que o rei era seu protetor, isto não impedia que membros do alto clero colocassem suas ambições pessoais acima dos interesses da instituição religiosa da qual faziam parte.

Mas apesar do fato citado, é inquestionável a extrema aproximação entre a coroa francesa e a Igreja, durante o reinado do soberano por nós focalizado, aproximação esta que explica a expressão "a França, filha primogênita da Igreja", pronunciada por um pontifice durante o reinado de Luís VI.

\footnotetext{
8 Id. ibid. p. 35.
}

9 CALMETTE, Joseph. Le Monde Féodal. Paris: Les Presses Universitaires de France. p. 317. 
Este fato oferece diversos aspectos à consideração do historiador, pois se, por um lado, isto fornecia à monarquia uma base ideológica que gerava uma legitimação - ímpar e incontestável, pois enraizava-se no próprio cerne da mentalidade medieval - por outro, trazia-lhe inúmeros problemas, que algumas vezes eram alheios aos interesses da coroa francesa.

É por este prisma que devemos analisar o conflito entre Luís VI e Henrique V, imperador alemão, que via no rei francês um inimigo por causa da amizade deste último com o pontifice romano.

A querela entre o papado e o império alemão apresentava-se como uma prova de força em que cada competidor pretendia impor ao outro a sua autoridade.

Esta situação de disputa entre o poder espiritual e o temporal na verdade encobria interesses também de ordem material e arrastava-se desde 1076 quando o papa Gregório VII proibiu que os bispos recebessem seu cargo das mãos de um leigo. A ordem papal foi contestada pelo imperador alemão, habituado que estava a conduzir a Igreja alemã e a usar seus recursos como se pertencessem à própria coroa.

A disputa estendeu-se no tempo e no espaço, pontilhada de lances que vão do pitoresco ao dramático, mas que não nos cabe aqui narrar. $O$ que não podemos deixar de referir é que a França sempre foi vista como uma aliada e uma defensora do papado e o seu território como um abrigo seguro para os papas quando estes ameaçados pelas tropas imperiais precisavam deixar a península itálica.

É em território francês que Calisto II preside um grande concilio (em Reims) ao

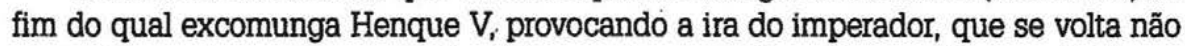
somente contra o papa, mas também contra o rei francês que dera acolhida ao pontífice.

"[...] L'empereur avait depuis longtemps conçu en son coeur de la rancune contre notre seigneur le roi Louis, celà à cause de l'anathème dont il s'était vu frapper dans le royaume de ce dernier, à Reims au concil tenu par le seigneur Calixte. Dans le temps qui précéda le décès de celui-ci, il rassembla un ost aussi considerable que possible de Lorrains, d'Allemands, de Bavarois, de Sonabes et, quoique en butte à leurs ataques, de Saxons sur le conseil du roi d'Angleterre Henri, dont il avait fait la fille reine en l'epousant et qui lui-même prenait l'offensive contre le roi Louis $[. . .]^{10}{ }^{10}$

Ao analisarmos a política européia deste período vamo-nos deparar com um complicado jogo de forças em que cada elemento tenta preponderar sobre os demais sem, contudo, consegui-lo. Mas é interessante observarmos que uma série de acontecimentos acabaram por criar elementos que, nascidos dentro do próprio feudalismo, apresentam-se contrários a ele. Senão, qual seria o interesse do rei inglês ao apoiar o alemão em sua luta contra Luís VI? Podemos creditar a ajuda prestada somente como um ato de solidariedade entre parentes?

$\mathrm{Na}$ verdade, a explicação para tais indagações surge com a análise das relações entre França e Inglaterra após a conquista desta última pelos normandos em 1066. Se o antagonismo entre o imperador alemão e o rei francês explica-se - como já dissemos - pela estreita ligação entre o Vaticano e Luís VI, o mesmo não ocorre em relação à Inglaterra.

10 SUGER. p. 219. 
Como bem sublinhou Calmette, a conquista normanda da Inglaterra criou uma situação impar dentro do sistema feudạl, ou seja, o rei inglês permanecia de posse da Normandia em solo francês, sendo assim, concomitantemente, rei no território insular e duque-vassalo na Normandia.

Ora, isto não se constituía somente uma ruptura no equilibrio de forças, mas a criação de uma antinomia que não podia ser vivida sem que periodicamente estourassem conflitos, os quais encontravam-se sempre latentes.

No jogo político, peça importante era sem dúvida o estabelecimento de laços de solidariedade, através de uma planejada e bem executada política de casamentos, cujo exemplo mais evidente foi o enlace entre Matilde, filha de Henrique I da Inglaterra, neta de Guilherme, o conquistador, com o imperador alemão Henrique V. A morte do irmão de Matilde em 1020, num naufrágio, fez da imperatriz herdeira do trono inglês, o que sem dúvida, representava uma séria ameaça à França.

Os laços de parentesco originados destes casamentos também eram um elemento complicador para o poder real quando ele necessitava do concurso de seus vassalos numa guerra. Exemplo disso encontramos na crônica de Suger:

"Lorsque le comte palatin Thibaut en personne, cédant à l'adjuration de la France, bien qu'il fit la guerre au roi avec son oncle le roi anglais, fut arrivé en compagnie de son oncle, le noble comte de Troyes Hugues, le roi forme une quatrième bataille". ${ }^{11}$

Se a guerra contra o imperador pôde ser vencida com facilidade, pois a invasão teutônica catalisou a solidariedade da maior parte da nobreza francesa em torno do rei, o mesmo não ocorre em relação à Inglaterra, devido à peculiar situação do rei inglês frente ao seu soberano francês.

As guerras contra o reino inglês pontilharam toda a Idade Média e só se encerraram no fim da Guerra dos Cem Anos, no séc. XIV, quando os destinos dos dois reinos separaram-se definitivamente.

É interessante observar a maneira como o cronista retrata tanto o rei inglês quanto o imperador alemão. Ambos foram inimigos de Luís, mas as palavras usadas pelo cronista são bem diferentes de um para outro. A diferença de tratamento encontra-se justamente na relação destes reis com a Igreja. Aquele que respeita a autoridade papal e os bens eclesiásticos é apresentado sob uma luz claramente benéfica.

A obra de Suger, ao iniciar-se, narra a oposição entre o país de Luís e de Guilherme II, o ruívo, rei da Inglaterra. Este último que nunca respeitou a Igreja, sendo um notório simoníaco, é retratado de forma pouco favorável e o cronista interpreta a morte deste rei - abatido por uma flecha numa floresta - como um golpe da justiça divina.

O sucessor de Guilherme, no entanto, é tratado de maneira bem diferente e isto não nos espanta, visto que Henrique I, logo ao subir ao trono, dá garantias à Igreja anglicana de que não praticaria a simonia.

"[...] Henri, um homme de grand courage, illustre dans la paix et dans le guerre. Son admirable grandeur éclate presque dans l'univers entier". ${ }^{12}$

11 SUGER. p. 225.

12 SUGER. p. 98. 
Uma avaliação da atuação de Luís VI frente aos destinos da França medieval ine é francamente favorável, pois durante o seu governo mostrou uma incansável disposição em fazer respeitado o poder real. Contudo, não devemos superestimar seus êxitos, pois embora tenha conseguido aplacar o baronato, o prestígio real permanece limitado. Isto pode ser provado quando sabemos que duas tentativas de Luís, uma na sucessão do feudo de Flandres e outra quanto ao condado de Auvergne e ao ducado de Guyenne, mostra que este prestígio ainda estava limitado pelos grandes senhores.

Como Felipe I, Luís VI sofreu a influência de sua entourage e é a esta que se creditam muitos de seus erros. Não podemos esquecer que a herança deixada por seu pai era um fardo muito pesado que limitou sua ação. Seu espírito simples e pouco afeito às sutilezas do jogo político também foi um fator limitante aos seus objetivos. Dotado de admirável energia e indomável coragem, Luís VI foi sobretudo um guerreiro. Seu reinado reveste-se de um significado decisivo para o destino da dinastia e da própria nação francesa, pois "graças a ele, se funda essa grande tradição capetíngia que contém em germe todas as promessas pois tende a nada mais, nada menos, que recompor o Estado e a França". ${ }^{13}$

Não podemos encerrar este modesto trabalho sem fazermos uma última reflexão, visto que ela se impõe ao historiador, sob a forma de algumas indagações: Este retrato tão favorável do rei Luís VI, pintado pelo cronista, corresponde de fato à realidade? Terá sido ele tão corajoso e piedoso quanto o autor nos quer fazer acreditar? $\mathrm{O}$ fato de Suger ser um membro do clero e Luís VI ter sido obediente ao papado não terá induzido o abade a enfocar o rei sob um prisma altamente positivo? E por fim, qual o grau de isenção de uma obra escrita cujo autor viveu de perto os acontecimentos narrados? Este fato não limita o valor histórico desta crôni$\mathrm{ca}$ ?

Para tentar responder a estas indagações é necessário recordarmos alguns pontos da biografia do abade Suger.

A trajetória de Suger, caracterizada pela ocupação de cargos importantes na corte de Luís VI, constituiu-se uma exceção para aqueles que não nasceram em berço nobre, como era o seu caso.

A origem do abade é um tanto nebulosa, mas é certo que pertencia a um estrato social bem modesto e que nasceu em Saint Denis ou Argentuil, tendo dois irmãos, Pierre e Raoul.

Ao ser enviado à abadia de Saint Denis (1094-1104), trava conhecimento com o princípe Luís que se encontrava nesse monastério enviado pelo pai quando de suas segundas núpcias. A amizade iniciada neste momento fará com que Suger participe ao lado do rei dos mais importantes acontecimentos de sua época afastando-se de seu lado apenas para encarregar-se das altas funções, inerentes à sua carreira eclesiástica, funções às quais, provavelmente, teve mais fácil acesso em decorrência de amizade com o rei.

Sua vida, então, passa a ser dividida entre sua abadia a qual depurou, enriqueceu e dotou de uma magnífica basílica, e a politica, como conselheiro do rei. 
É difícil precisarmos as etapas de sua carreira, mas em episódios importantes para o reino ele teve atuação de destaque. É na qualidade de embaixador junto ao papa que assiste ao Concilio de Latrão presidido por Pascal II. Em 1118 saúda oficialmente Gelásio. Em janeiro de 1122 é enviado à Itália para tratar com Calixto II de "certos casos do reino".

Está presente também no Concílio Geral de Latrão em março de 1123. Em agosto de 1125 acredita-se que Suger de alguma forma contribuiu para o triunfo de Lotário na eleição para a sucessão de Henrique V.

Após ser eleito abade de Saint Denis (1122) vemos sua presença de forma menos constante na corte embora nos momentos vitais estivesse sempre presente, como no dia 14 de abril de 1129, quando da coroação do principe Felipe, bem como em outubro de 1131 por ocasião da morte acidental deste mesmo princípe. É ele quem acompanha, em julho de 1137, o princípe Luís de Bordeaux onde iria desposar Eleonora d'Aquitânia.

Embora afirme-se que de 1127 a 1137 não tenha intervindo em casos políticos, há um fato que constitui exceção, é quando em 1130 é enviado por Luis VI a acolher e saudar o fugitivo pontífice Inocêncio II.

Até nos derradeiros momentos de Luís VI comprovamos a sua influência a aconselhar o soberano à reconciliação de seu primo Raoul de Vermandois com Thibaut de Chartres.

Com a morte do rei, Suger irá enfrentar uma crise, pois a rainha Adelaide e Raoul de Vermandois, ciumentos de sua influência junto ao novo soberano, Luís VII, a ele opuseram-se. Tal oposição não parece ter abalado a posição do abade na corte, pois em 1138 acompanha Luís VII na expedição a Poitiers onde aconselha o inexperiente rei, fazendo com que este modere o arrebatamento de sua juventude, o que faz com que 0 episódio da Comuna de Poitiers tenha um término feliz. Nas intrigas que grassam entre Raoul de Vermandois, o rei e Thibaut de Chartres, procura não tomar parte, mas em 1144 unido a S. Bernardo faz cessar a guerra entre Thibaut e o rei.

Em 1147 sua fama de conciliador, supomos também de bom administrador, faz com que seja designado para a mais alta função de sua vida: exercer a regência do reino durante a ausência do rei que partira para a Cruzada.

A enorme influência que exerceu junto a dois soberanos, sua fama de conciliador, de artífice da paz, naturalmente granjeou-lhe a inveja de inúmeras pessoas, tanto na corte quanto no meio eclesiástico. O próprio $\mathrm{S}$. Bernardo teceu exarcebadas críticas acerca da atuação de Suger, o qual considerava mais preocupado em servir a dinastia francesa do que a causa da Igreja.

A crítica não nos parece pertinente pois o retrato moral que podemos traçar do abade é de um homem inteligente, habilidoso, devotado à Igreja sem ser, no entanto, um fanático, preocupado com a segurança do reino e extremamente fiel a seu rei. Um espírito lúcido e moderado que não se deixava envolver pelas intigras palacianas.

Naturalmente não podemos deixar de perceber que a Vie de Louis De Geos foi escrita com o claro objetivo de louvar as ações de Luís VI durante o seu reinado de trinta anos. 
Mas isso não diminuiu a importância histórica da obra, sendo ela um importante documento histórico, justamente porque o autor vivenciou os acontecimentos narrados - em muitos deles como testemunha ocular - aliado ao fato de ser uma pessoa instruída, segundo outros testemunhos, e possuir uma execelente memória.

Como qualquer fonte histórica, a obra de Suger deve ser lida e avaliada de forma critica, pois sabemos que a amizade que ligava o autor ao biografado pode têlo feito, não distorcer os acontecimentos - isso não acreditamos - mas, no mínimo, a enfocar as atitudes do rei sob uma ótica benevolente, exaltando-lhe os acertos e minimizando suas faltas, pois as censuras são feitas de forma velada e tolerantemente creditadas à pouca idade com que Luís começa a responsabilizar-se pelos destinos do reino; em idade mais avançada, atribuídas aos que o cercavam e cujas más ações, muitas vezes, nele refletiam-se.

Outro aspecto característico da obra de Suger é que ela é rica em considerações morais pois o autor credita sempre a derrota dos opositores do rei e inimigos da igreja a um merecido castigo divino originado por suas maldades, o que não nos causa nenhum espanto, visto ser próprio do mental coletivo da época.

Apesar de um entusiasta admirador do rei, podemos afirmar que é com ânimo sereno que ele analisou os principais acontecimentos de sua época, demonstrando - como já o dissemos - admiração por Henrique I da Inglaterra e chegando a afirmar que lamentava a luta entre os dois reis pois os dois reinos deveriam permanecer distintos, sem que um sobrepujasse o outro.

Essa mesma isenção ele demonstra em relação aos papas, pois embora use um tratamento respeitoso quando a eles se refere, não demonstra, contudo, nenhuma simpatia nem pelos melhores romanos.

Em suma, podemos afirmar que apesar do afeto que o unia a Luís VI, sua crônica é um documento confiável, pois a imagem real que ele nos apresenta não é uma imagem distorcida pela necessidade de louvar um soberano.

As virtudes que ele reconhece no monarca francês são aquelas que eram consideradas no período feudal as mais importantes e desejadas num soberano, isto é, a coragem e o espírito de justiça.

Em sua obra Suger deixa claro que a sua idéia de poder real é aquela que o identifica com a lei, isto é, na Idade Média, o bom soberano é, antes de tudo, o promotor da justiça, aquele que zela pela segurança e pela paz do seu reino; não 0 que exerce o poder de forma caprichosa e imoderada.

De tudo o que foi exposto podemos tirar algumas conclusões.

A primeira delas é que apesar da ideologia elaborada pelos doutores da Igreja e transmitida à população através dos sermões, afirmar que a sociedade humana era um reflexo da sociedade celeste e que cada ordem deveria viver em harmonia com as demais num clima de concórdia, isto na prática raramente ocorria.

Embora na Idade Média os homens temessem o castigo divino e o anátema da Igreja, a ambição falava mais forte e o baronato feudal freqüentemente cobiçava os bens do clero, fazendo das Igrejas alvo de sua rapacidade.

Esta atitude chocava-se frontalmente com o que era pregado pelos padres, que proclamavam que a cada ordem correspondia o exercício de uma função social, e que no caso da nobreza a sua função seria proteger as duas outras ordens, isto é, o clero e o povo. 
Outro elemento a ser considerado diz respeito à questão das investiduras que, iniciada no território do Sacro Império, propagou-se por toda a Europa, influenciando a política dos diversos reinos europeus, à medida que seus soberanos perfilavam-se a favor do papa ou do imperador.

$\mathrm{Na}$ verdade, era um embate que objetivava definir as atribuições do poder temporal e do espiritual que na Idade Média freqüentemente se confundiam. E esta confusão originava-se, sem dúvida, da legitimação que o segundo deva ao primeiro, mas que fazia com que tanto o rei como os papas se sentissem no direito de interferir tanto nos assuntos eclesiásticos quanto nos que se referiam à sociedade leiga.

Se o papa era o chefe da cristandade, o rei era o braço armado da Igreja. O primeiro como pastor de um único rebanho acreditava ser sua obrigação tudo fiscalizar e normatizar de forma que nenhum desvio alterasse a rota dos cristãos em direção ao Paraíso.

Os reis, por sua vez, apesar de beneficiarem-se da proteção moral que a Igreja lhes dispensava, sentiam-se também no direito de imiscuirem-se nos assuntos das igrejas de seus territórios.

Não causa, pois, espanto que Luís VI, ao passar sua vida a defender a Igreja e nunca tendo se aproveitado dos bens eclesiásticos, receba por parte de Suger, um abade, a gratidão pelos seus feitos. 